\title{
Interval between injection of contrast material and positive contrast cheliography affects accurate diagnosis of diaphragmatic hernia
}

\author{
Ismail A. Sen, M. Baris Akgul, Nihal Y. Gul Satar, Ayse Topal \\ Uludag University, Faculty of Veterinary Medicine, Department of Surgery, Nilufer, Bursa, Turkey
}

Received March 26, 2014

Accepted November 26, 2014

\begin{abstract}
The aim of this study was to evaluate the clinical, surgical and diagnostic imaging findings in 11 cats and 3 dogs with suspected acute and chronic traumatic diaphragmatic hernia, and to compare the results of positive contrast cheliography (peritoneography) taken immediately and 5 min after the injection of contrast material. Thoracic and abdominal radiography, ultrasonography, and positive contrast cheliography of all animals were performed. Eight cases were considered as acute and six cases were considered chronic. The contrast images taken immediately after the injection of contrast material revealed the contrast material in the thoracic cavity in $8 / 8$ acute trauma patients, but in none of the chronic cases. In $5 / 6$ of these cases contrast material was seen in the thoracal cavity only in additional images taken after $5 \mathrm{~min}$. One patient was diagnosed with FIP and excluded from the study. Twelve cases had complete resolution and one animal died during the early postoperative period. Our results suggest that positive contrast cheliography performed immediately after the injection of contrast material may not reveal chronic cases of diaphragmatic hernia and a second imaging (or imaging after $5 \mathrm{~min}$ ) is indicated in order not to overlook chronic cases.
\end{abstract}

Cat, chronic, contrast medium, diaphragm, dog, peritoneography

Traumatic diaphragmatic hernia most often develops as a result of blunt abdominal trauma (particularly motor vehicle accidents), resulting in sudden increase in abdominal pressure and subsequent disruption of the diaphragm which allows abdominal organs to migrate into the chest cavity (Schmiedt et al. 2003; Fossum 2007). Several reports in veterinary literature have described the pathophysiology, surgical approaches, and outcomes of traumatic diaphragmatic hernia (Wilson and Hayes 1986; Boudrieau and Muir 1987; Downs and Bjorling 1987; Minihan et al. 2004; Worth and Machon 2005).

Herniation of abdominal organs into the thoracic cavity may result in the inability of the lung to inflate and, thus, respiratory dysfunction (dyspnea, tachypnea, cyanosis) is the most common presenting sign of reduced functional residual capacity (Garson et al. 1980; Wilson 1992). Other clinical signs such as a "tucked" (empty) abdomen or the presence of muffled heart sounds and/or absent lung sounds are helpful, but variably present (Worth and Machon 2005).

Diaphragmatic hernia can be diagnosed by means of radiography, ultrasonography and surgery (Hay et al. 1989; Reichle and Wisner 2000; Hyun 2004; Kibar et al. 2006). Radiography is the initial imaging technique of choice in diagnosing traumatic diaphragmatic herniation and the most frequently reported radiographic findings are loss of the diaphragmatic line, masking of the cardiac shadow, dorsal or lateral displacement of lung fields, presence of gas stomach or intestines in the thoracic cavity, and pleural effusion (Garson et al. 1980; Sullivan and Lee 1989; Williams et al. 1998). Positive contrast cheliography (peritoneography) (Stickle 1984; Bumin et al. 1998; Kibar et al. 2006; Besalti et al. 2011) or noncardiac thoracic ultrasonography (Hay et al. 1989; Tidwell

Address for correspondence:

Nihal Y. Gul Satar

Department of Surgery

Faculty of Veterinary Medicine

Uludag University,16059 Nilufer/Bursa, Turkey
Phone: +90224 2940839

Fax: + 902242941202

E-mail: ngul@uludag.edu.tr

http://actavet.vfu.cz/ 
1998; Spattini et al. 2003; Minihan et al. 2004; Kibar et al. 2006) can be consulted to assist diagnosis in cases in which direct radiography proves to be inadequate. The liver is the most commonly herniated organ, with the stomach, small intestine, and spleen often involved in left-sided hernias, and the small intestine and pancreas in right-sided tears (Boudrieau and Muir 1987).

It is known that the passage of contrast material from the abdomen into the thoracic cavity may not occur if adhesions are present, particularly in chronic cases (Kibar et al. 2006). Therefore, we decided to evaluate the clinical, surgical, and diagnostic imaging findings in 11 cats and 3 dogs with suspected acute and chronic traumatic diaphragmatic hernia and to compare the diagnostic accuracy of positive contrast cheliography taken immediately or 5 min after the injection of contrast material.

\section{Materials and Methods}

A total of 14 patients that were referred to our Teaching Hospital between 2012 and 2014 with suspected traumatic diaphragmatic hernia were included in this study. Information about the animals are presented in Table 1.

For the radiographic diagnosis, dorsoventral and lateral thoracic and abdominal radiographs were taken. In nonconclusive cases, ultrasonography and positive contrast cheliography were also performed.

A $7 \mathrm{MHz}$ sector transducer was utilised during ultrasonographic examination (Sonoline Prima, Siemens, USA). Animals without dyspnea were laid on their right side, whereas animals displaying signs of dyspnea were maintained in dorsal position. The possible presence of abdominal organs in the thorax was bilaterally examined through the $5^{\text {th }}-13^{\text {th }}$ intercostal spaces on both the right and left sides. Furthermore, the abnormal position of the heart and the presence of pleural fluid were also evaluated during this examination.

For positive contrast cheliography, animals were laid down on their left side. After routine presurgical preparation, sterile contrast material (Iohexol, Omnipaque ${ }^{\circledR}, 300 \mathrm{mgI} / \mathrm{ml}$, GE Healthcare, Ireland) was slowly injected into the abdominal cavity at a dose of $1.1 \mathrm{mg} / \mathrm{kg}$. Upon entry of the abdominal cavity with the needle, the piston of the injector was withdrawn and aspiration performed so that possible puncture of the abdominal organs could be revealed. The presence of air bubbles in the injector was indicative of the needle being located in the peritoneal cavity. The rear part of the animals was slightly elevated to ease the flow of the contrast material into the thoracic cavity if herniation was present (Kibar et al. 2006). Radiographs were taken in right and left latero-lateral and dorso-ventral positions immediately after injection. If the diagnosis of herniation was confirmed by positive contrast cheliography, the animal was referred for operation; in other cases a second positive contrast cheliography was performed after $5 \mathrm{~min}$.

In cases to undergo surgery, dexamethasone $(0.5 \mathrm{mg} / \mathrm{kg}$, i.v. $)$ was administered immediately preoperatively to prevent reexpansion injury of lungs. General anaesthesia was induced with propofol (Diprivan ${ }^{\circledR}, 6 \mathrm{mg} / \mathrm{kg}, \mathrm{i} . \mathrm{v}$., AstraZeneca, Turkey), or with diazepam (Diazem ${ }^{\circledR}, 0.2 \mathrm{mg} / \mathrm{kg}$, i.v., Deva, Turkey) and ketamine (Alfamine ${ }^{\circledR}$, $5 \mathrm{mg} / \mathrm{kg}$, i.v., Egevet, Turkey) combination, and maintained with isoflurane (Forane ${ }^{\circledR}$, Abbott, United Kingdom) delivered in oxygen via a circle system using a small animal anaesthetic machine (AMS 200, AMS, Turkey). The patients were positioned in dorsal recumbency with the head positioned toward the top of the table and the table tilted at 40 degrees to facilitate gravitation of abdominal viscera from the thorax. All dogs breathed $\times 12-14 / \mathrm{min}$ and cats $\times 16-18 / \mathrm{min}$ and an inspiratory:expiratory (I:E) ratio of 1:2 to achieve a target end-tidal $\mathrm{CO}_{2}$ between 35 to $45 \mathrm{~mm} \mathrm{Hg}$ positive pressure ventilation with an automatic ventilator. Lactated Ringer's solution was administered at $10 \mathrm{ml} / \mathrm{kg} / \mathrm{hr}$ during anaesthesia. Cephazoline sodium (Iespor ${ }^{\circledR}, 20 \mathrm{mg} / \mathrm{kg}$, i.v., I. E. Ulagay) was administered to prevent infection. Analgesia was provided with tolfenamic acid (Tolfedine ${ }^{\circledR}$, $4 \mathrm{mg} / \mathrm{kg}$, p.o., Novakim) administered postoperatively for 3 days.

Surgical herniorrhapy was carried out via a ventral midline celiotomy approach to the diaphragm in all cases. Then abdominal organs in the thoracic cavity were drawn into the abdominal cavity and cleaned with Ringer's lactate solution and rifamycin (RIF ${ }^{\circledR}$, Kocak Farma Inc., Turkey). Hernia was repaired with monofilament polyglactin 910 (Vicryl $^{\circledR}$, Ethicon, United Kingdom) absorbable suture material in pattern of simple interrupted $\mathrm{X}$ form. After repairing the hernia, thoracocentesis was carried out with a three ways cannula placed through the diaphragm and the air within the thorax was aspirated with an injector to achieve negative pressure. The linea alba and skin were closed routinely. Postoperative radiographs were taken and range of pneumothorax and diaphragmatic line were controlled.

\section{Results}

The aetiology of trauma and duration between the incident and referral are presented in Table 1. The cases admitted for surgery in less than 15 days were accepted as acute ( 8 cases), and more than 15 days were considered chronic (6 cases) diaphragmatic hernia. 


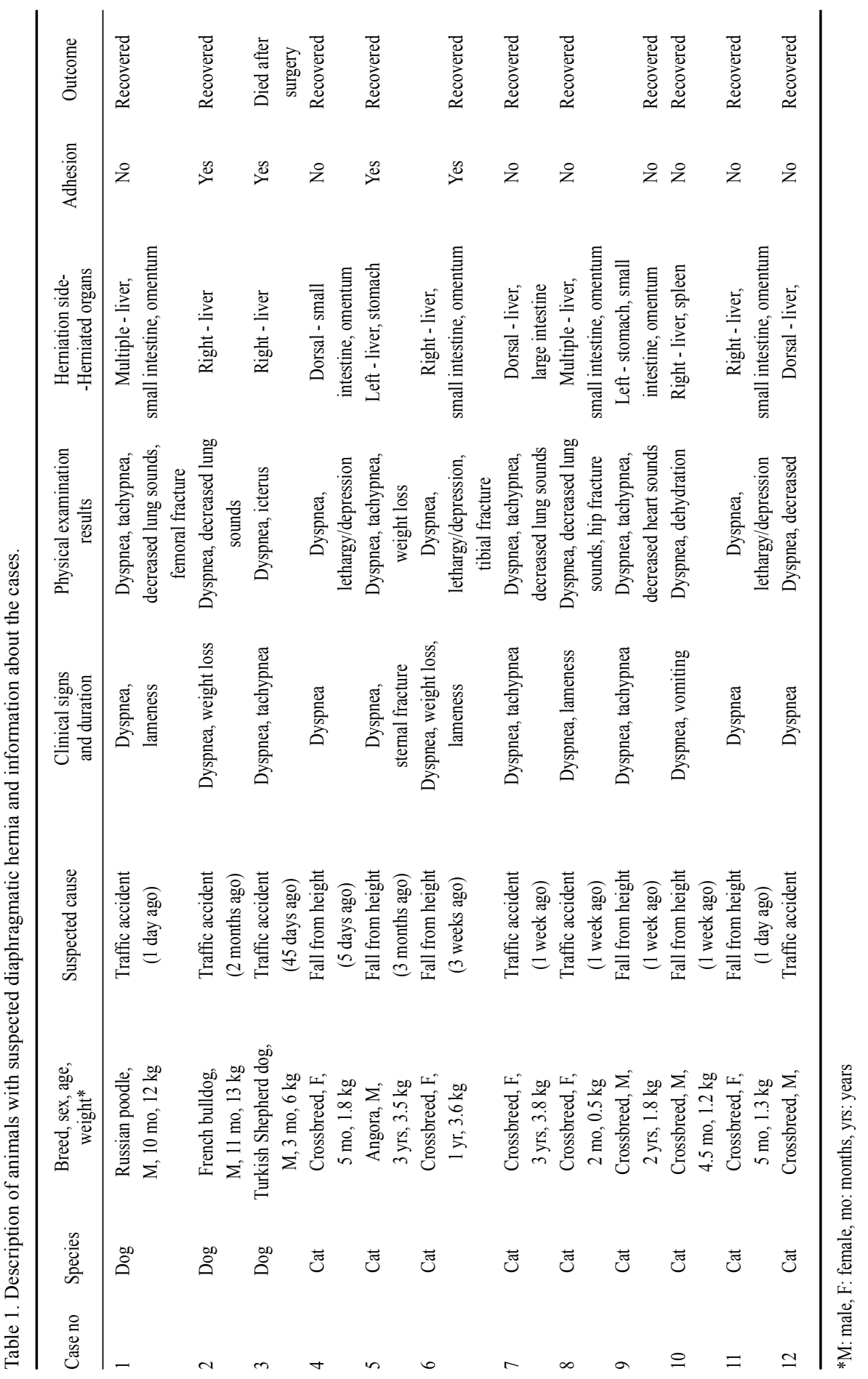


For dogs, the mean heart rate at presentation was $102 \pm 15$ beats per min (range: 92-120 bpm); the mean respiratory rate was $55 \pm 13$ breaths per min (range: 40-64); and the mean temperature was $37.7 \pm 2.80^{\circ} \mathrm{C}$ (range: $35.7-39.5^{\circ} \mathrm{C}$ ). For cats, the mean heart rate at presentation was $106 \pm 35$ beats per min (range: $80-180 \mathrm{bpm}$ ); the mean respiratory rate was $50 \pm 11$ breaths per minute (range: 40-72); and the mean temperature was $38.1 \pm 2.50^{\circ} \mathrm{C}$ (range: $35.6-39.7^{\circ} \mathrm{C}$ ). A complete blood cell count and serum biochemical profile were evaluated in all cases. Abnormalities included elevation of ALT (alanine transaminase; $68 \mathrm{U} / 1$ ), AST (aspartate aminotransferase; $57 \mathrm{U} / 1$ ), and total bilirubin $(0.72 \mathrm{mg} / \mathrm{dl})$ in case 3 , which had icterus. In case 14 , white blood cell count (WBC) was $22,000 / \mu$ land the animal had neuthrophilic leukocytosis.

Clinical signs that may be attributed to a diaphragmatic hernia included coughing, tachypnea, dyspnea, vomiting, or weight loss. Surgical findings that were indicative of chronicity included absence of bruising in the body wall or diaphragm, absence of blood in the thoracic or abdominal cavities, presence of mature adhesions to or between the herniated tissues, and presence of mature fibrosis over the hernia margins.

According to thoracic and abdominal radiographs, diaphragmatic hernia was documented in five (35.71\%) animals due to loss of diaphragmatic detail and soft tissue opacity within the thoracic cavity. Abdominal ultrasonography was performed in all animals. In positive contrast cheliography, the contrast material injected into the peritoneal cavity passed into the thorax in $13(92.85 \%)$ patients. In eight patients $(57.14 \%)$ considered having acute hernia, the pass was seen in radiographs taken immediately, whereas in other five patients $(35.71 \%)$ considered having chronic hernia, an additional radiography was performed after $5 \mathrm{~min}$ and the pass was seen in the thorax (Plate VIII-X, Figs 1-3). The contrast material did not pass into the thoracic cavity in case 14. In this case, the contrast material spread to the abdominal cavity and diaphragmatic border became more visible, but no diaphragmatic rupture was observed. The cat had a pleural effusion and puncturing revealed chylothorax; additional FIP (Feline infectious peritonitis) test was positive. The animal was diagnosed as having FIP and removed from the study. Concomitant fractures were observed in four cases $(28.57 \%)$ upon clinical and physical examination and/or radiographs (Table 1).

After being diagnosed as having diaphragmatic hernia, thirteen patients were operated with midline laparotomy. Herniation was most commonly one-sided $(\mathrm{n}=11$; $84.62 \%)$, followed by right-sided herniation $(n=5$, 
$38.46 \%)$. Liver was the most common herniated organ $(n=11 ; 84.62 \%)$, followed by small intestine and omentum $(n=7 ; 53.85 \%)$. The herniated organs were pulled back into the abdominal cavity before herniorrhaphy (Plate XI, Fig. 4).

In all the cases considered as chronic, mature adhesions between the lungs or edges of the diaphragm and herniated organs were noted during surgery; pleural effusion was not significant. Following hernia reduction, spontaneous reexpansion of the lungs was noted in the capnography records in all animals. None of the animals required a muscle flap or mesh graft to close the hernia defect. In postoperative radiographs, diaphragmatic border was seen clearly and no pathological findings, such as pneumothorax, were observed. One patient (case no. 3) with liver herniation developed fatal complications due to liver failure during the early postoperative period and died despite all efforts. Twelve animals were discharged from the hospital. Follow-up communication with the owners revealed that the patients had no complications or any evidence of recurrence during the 4-12 (mean 6.2) months of the follow-up period.

\section{Discussion}

Advances in surgical and anaesthetic management of traumatic diaphragmatic herniation contributes to the improved outcome (Worth and Machon 2005). More recently, Bellenger et al. (1996) reported survival rates of $78 \%$ for dogs and $92 \%$ for cats undergoing surgical repair of traumatic diaphragmatic hernias, whereas Schmiedt et al. (2003) reported a survival rate of $82 \%$ in their study of 34 cats. The largest study to date was reported by Downs and Bjorling (1987). In that study analyzing 1,674 cases, overall mortality rates in dogs with acute and chronic diaphragmatic hernias were $27.8 \%$ and $26.2 \%$, and the mortality rates in cats with acute and chronic diaphragmatic hernias were $20 \%$ and $11.8 \%$, respectively. In our study, only one animal died and the mortality rate was $7.69 \%$.

Diaphragmatic hernia is common in animals between 1-3 years of age (Stokhof 1986) and occurs more often in males (Stokhof 1986; Bellenger et al. 1996; Schmiedt et al. 2003; Hyun 2004; Minihan et al. 2004). The anatomical position of the organ and the location of the disruption often determine the herniated organs in diaphragmatic hernia. In several studies, including our current study, the liver has been found the most commonly herniated organ followed by the small intestine, stomach, omentum, spleen, pancreas, and large intestine (Schmiedt et al. 2003; Hyun 2004; Gibson et al. 2005).

In diaphragmatic hernia cases, the interval from trauma to intervention can be as long as one year (Besalti et al. 2011). Cases with a history of more than 2 weeks are usually considered chronic and treatment is often intricate, sometimes resulting in death due to pneumothorax, complications during the breakdown of the adhesions, liver lobe torsion or necrosis, or strangulation of the intestines within the hernial ring (Minihan et al. 2004). A mortality rate as high as $5 / 21$ cases has been found in one study (Besalti et al. 2011). In our study, one patient (case no. 3) died because of liver failure; the interval from trauma to surgery was three months in this animal.

Diaphragmatic hernia is usually secondary to trauma and is commonly accompanied with rib fractures, pulmonary contusions, traumatic myocarditis, haemothorax, and shock (Slensky 2009). In our study, we detected fractures accompanying diaphragmatic hernia in 4 cases.

Radiographic diagnosis is the single most important diagnostic method of detecting diaphragmatic hernia in dogs and cats, although it is not always easy to identify diagnostic radiographic signs, especially in cases with pleural effusion (Hyun 2004; Fossum 2007). A complete study to rule out subtle or small diaphragmatic hernias in stable patients should include left and right lateral, dorsoventral, and ventrodorsal radiographs (Worth and 
Machon 2005). Additional imaging techniques such as contrast radiography (gastrography or peritoneography), ultrasonography, computed tomography (CT) scans or magnetic resonance imaging (MRI) may be necessary since plain thoracic radiographs do not always provide a definitive diagnosis (Stickle 1984; Hunt and Johnson 2003; White et al. 2003; Minihan et al. 2004; Worth and Machon 2005; Slensky 2009).

Barium contrast radiography, given via the oral route, does not reveal diaphragmatic hernia in many cases when the liver and spleen are the herniated organs (Sullivan and Lee 1989). In our study, positive contrast celiography was the most helpful supplemental imaging technique. The contrast material passed into the thorax in $13(92.85 \%)$ patients. In $8(61.54 \%)$ of these cases which were considered acute, the pass was seen in radiographs taken immediately, whereas in the other 5 patients $(38.46 \%)$ with chronic trauma, the pass was seen only in additional radiographs taken at the $5^{\text {th }}$ minute. Previously, some researchers have stated that the passage of contrast material into the thoracic cavity might not occur if adhesions were present (Kibar et al. 2006). Thefore, in our study additional images were taken after $5 \mathrm{~min}$ in cases which were considered as chronic and where the first images did not reveal herniation.

Removal of the abdominal organs from the thorax to the abdomen rarely causes difficulty. In certain cases in which the abdominal organs protrude into the thoracic cavity, adhesions have been reported to be either between the internal organs or between the internal organs and the diaphragm (Bumin et al. 1998; Tidwell 1998; Minihan et al. 2004; Besalti et al. 2011). Johnson (1993) reported that intrathoracic adhesions are uncommon, even in long-standing cases of herniation, but should be carefully dissected to avoid lacerating major vessels. We detached the adhesions by gentle dissection and herniated contents were replaced into abdominal cavity into its normal position. There were no complications with stitches or recurrence of hernia during the follow-up period. Reccurrence rates of $4 \%$ in dogs and 5.6\% in cats have been reported previously (Stokhof et al. 1986).

In conclusion, our data indicate that the time interval between the injection of the contrast material into the abdominal cavity and the time positive contrast cheliography affects the accurate diagnosis of diaphragmatic hernia. Leaving an interval between injection and cheliography, particularly in chronic cases where adhesions might have formed, can be a sensible approach in order not to overlook these cases.

\section{Acknowledgement}

The authors would like to thank Dr. I. Taci Cangul for his editorial assistance.

\section{References}

Bellenger CR, Hunt GB, Goldsmid SE, Pearson MR 1996: Outcomes of thoracic surgery in dogs and cats. Aust Vet J 74: 25-30

Besalti O, Pekcan Z, Calıskan M, Aykut ZG 2011: A retrospective study on traumatic diaphragmatic hernias in cats. Ankara Univ Vet Fak Derg 58: 175-179

Boudrieau R, Muir W 1987: Pathophysiology of traumatic diaphragmatic hernia in dogs. Compend Contin Educ Vet 9: 379-384

Bumin A, Alkan Z, Temizsoylu MD, Sarierler M 1998: Positive contrast cheliography in dogs and cats (peritoneography) (in Turkish). Turkish J Vet Surg 4: 19-22

Downs MC, Bjorling DE 1987: Traumatic diaphragmatic hernias: a review of 1674 cases (Abstract). Vet Surg 16: 87

Fossum TW 2007: Surgery of the lower respiratory system: pleural cavity and diaphragm. In: Fossum TW (Ed.): Small Animal Surgery. $3^{\text {rd }}$ edn. Mosby Elsevier, St. Louis, pp. 896-929

Garson HL, Dodman NH, Baker GJ 1980: Diaphragmatic hernia: analysis of fifty-six cases in dogs and cats. J Small Anim Pract 21: 469-481

Gibson TWG, Brisson BA, Sears W 2005: Perioperative survival rates after surgery for diaphragmatic hernia in dogs and cats: 92 cases (1990-2002). J Am Vet Med Assoc 227: 105-109

Hay WH, Woodfield JA, Moon MA 1989: Clinical, echocardiographic, and radiographic findings of peritoneopericardial diaphragmatic hernia in two dogs and a cat. J Am Vet Med Assoc 195: 1245-1248 
Hunt GB, Johnson KA 2003: Diaphragmatic, pericardial, and hiatal hernia. In: Slatter D (Ed.): Textbook of Small Animal Surgery. $3^{\text {rd }}$ edn. WB Saunders, Philadelphia, pp. 471-488

Hyun C 2004: Radiographic diagnosis of diaphragmatic hernia: review of 60 cases in dogs and cats. J Vet Sci 5: 157-162

Johnson KA 1993: Diaphragmatic, pericardial, and hiatal hernia. In: Slatter D (Ed.): Textbook of Small Animal Surgery. $2^{\text {nd }}$ edn. WB Saunders, Philadelphia, pp. 455-470

Kibar M, Bumin A, Kaya M, Alkan Z 2006: Use of peritoneography (positive contrast cheliography) and ultrasonography in the diagnosis of diaphragmatic hernia: review of 35 cats. Revue Méd Vét 157: 331-335

Minihan AC, Berg J, Evans KL 2004: Chronic diaphragmatic hernia in 34 dogs and 16 cats. J Am Anim Hosp Assoc 40: 51-63

Reichle JK, Wisner ER 2000: Non-cardiac thoracic ultrasound in 75 feline and canine patients. Vet Radiol Ultrasound 41: 154-162

Schmiedt CW, Tobias KM, Stevenson M 2003: Traumatic diaphragmatic hernia in cats: 34 cases (1991-2001). J Am Vet Med Assoc 222: 1237-1240

Slensky K 2009: Thoracic trauma. In: Silverstein D, Hopper K (Eds): Small Animal Critical Care Medicine. $1^{\text {st }}$ edn. Saunders Elsevier, St. Louis, pp. 662-667

Spattini G, Rossi F, Vignoli M, Lamb CR 2003: Use of ultrasound to diagnose diaphragmatic rupture in dogs and cats. Vet Radiol Ultrasound 44: 226-230

Stickle RL 1984: Positive-contrast celiography (peritoneography) for the diagnosis of diaphragmatic hernia in dogs and cats. J Am Vet Med Assoc 185: 295-298

Stokhof AA 1986: Diagnosis and treatment of acquired diaphragmatic hernia by thoracotomy in 49 dogs and 72 cats. Vet Q 8: 177-183

Sullivan M, Lee R 1989: Radiological features of 80 cases of diaphragmatic rupture. J Small Anim Pract 30: 561-566

Tidwell AS 1998: Ultrasonography of the thorax (excluding the heart). Vet Clin North Am Small Anim Pract 28: 993-1015

White JD, Tisdall PL, Norris JM, Malik R 2003 Diaphragmatic hernia in a cat mimicking a pulmonary mass. J Feline Med Surg 5: 197-201

Williams J, Leveille R, Myer CW 1998: Imaging modalities used to confirm diaphragmatic hernia in small animals. Compend Contin Educ Vet 20: 1199-1211

Wilson DV 1992: Anesthesia for patients with diaphragmatic hernia and severe dyspnea. Vet Clin North Am Small Anim Pract 22: 456-459

Wilson GP 3rd, Hayes HM Jr 1986: Diaphragmatic hernia in the dog and cat: a 25-year overview. Semin Vet Med Surg (Small Animal) 1: 318-326

Worth AJ, Machon RG 2005: Traumatic diaphragmatic herniation: pathophysiology and management. Compend Contin Educ Vet 27: 178-190 
Sen I. A. et al.: Interval between ... pp. 173-179

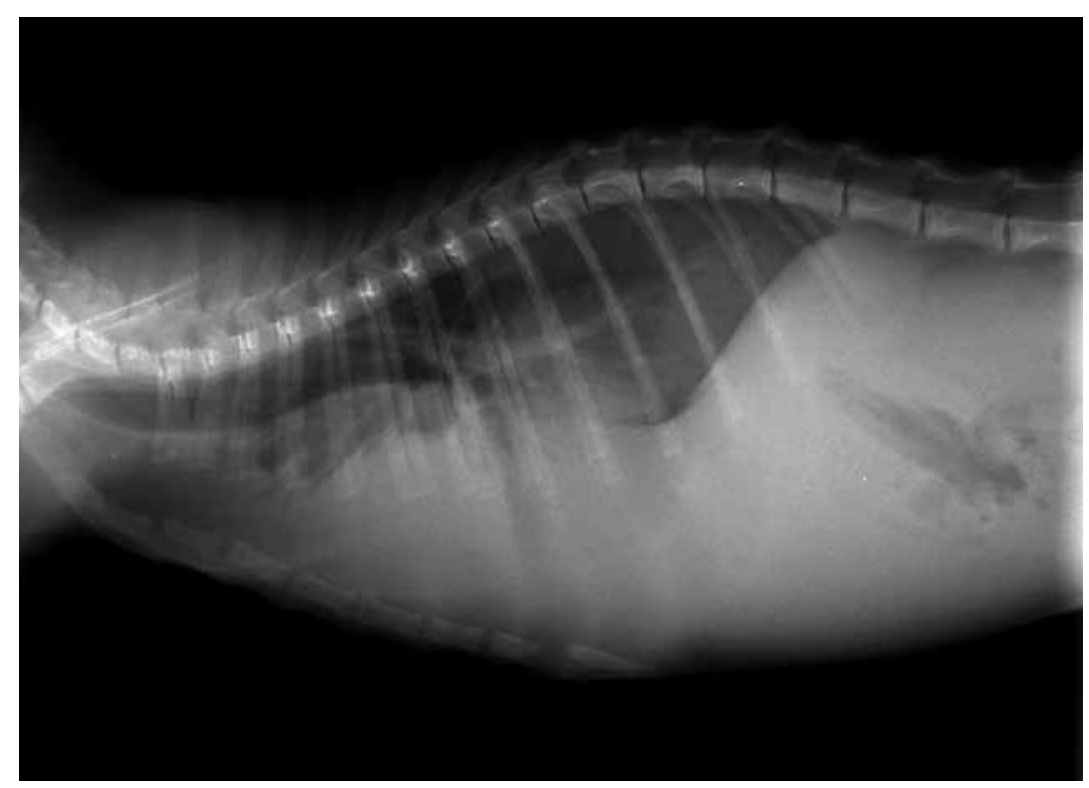

Fig. 1. Right lateral thoracic and abdominal radiographic view of a 1-year-old crossbreed cat with diaphragmatic hernia (Case 6). Notice that the diaphragmatic line is lost and a soft tissue opacity is located within the thoracic cavity. The characteristic abdominal gas shadow is also observed. The cardiac shadow is completely obliterated due to pleural effusion and the invasion of abdominal organs. 


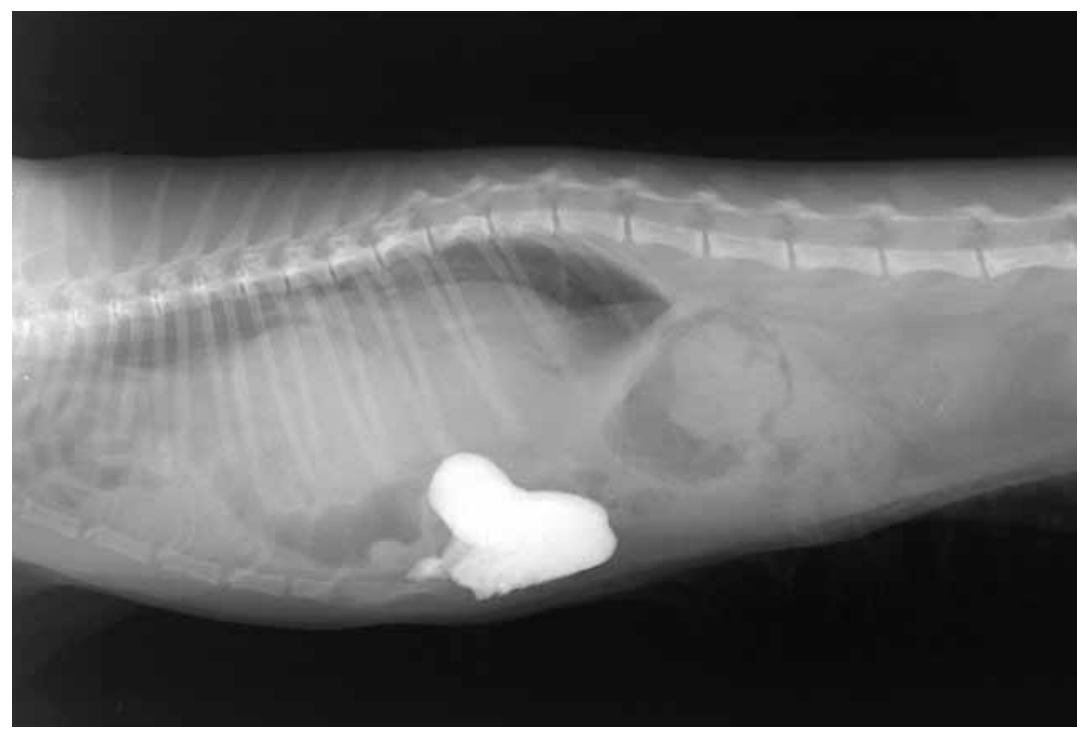

Fig. 2a. Right lateral thoracic and abdominal cheliographic view of the same case. The radiograph was taken immediately after the injection of the contrast material. The contrast material can not be seen in the thoracal cavity because of adhesions in this chronic case.

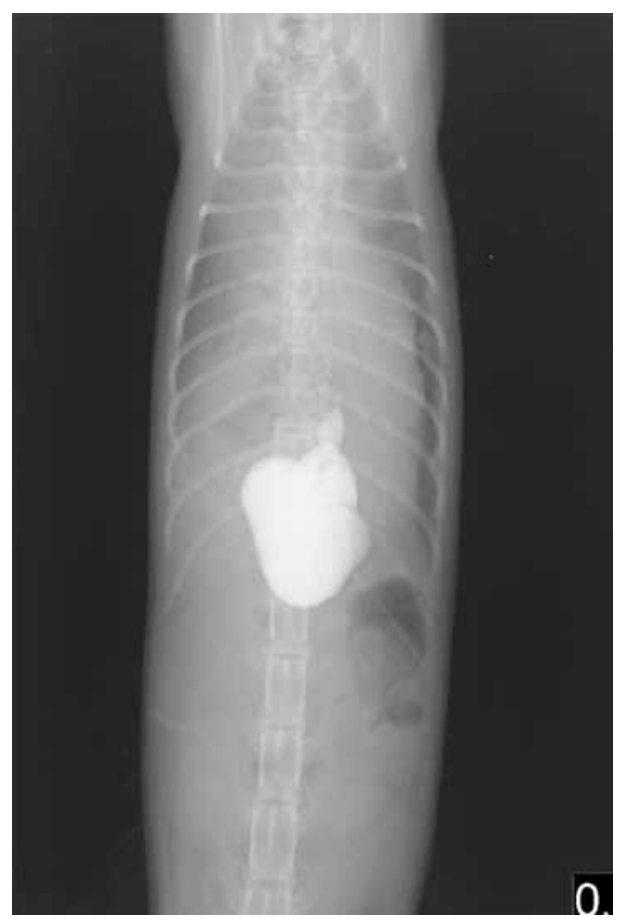

Fig. 2b. Dorsoventral thoracic and abdominal cheliographic view of the same case. The radiograph was taken immediately after the injection of the contrast material. 


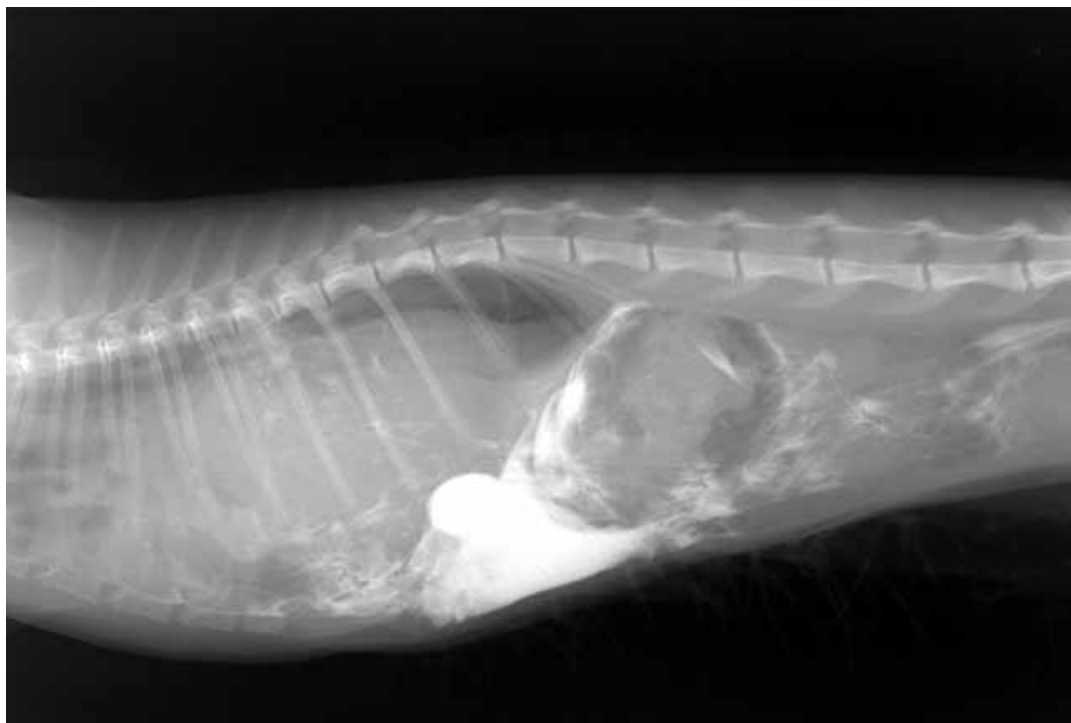

Fig. 3a. Right lateral thoracic and abdominal cheliographic view of the same case. The radiograph was taken 5 min after the injection of the contrast material. The normal outlines of the diaphragm and liver are absent and the presence of the contrast medium in the thoracic cavity is evident.

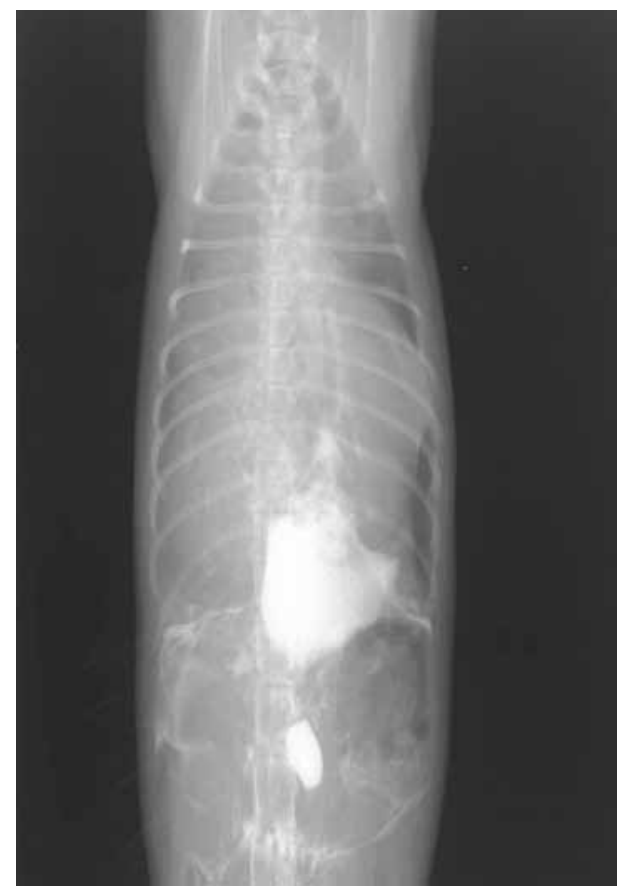

Fig. 3b. Dorsoventral thoracic and abdominal cheliographic view of the same case. The radiograph was taken 5 min after the injection of the contrast material. 


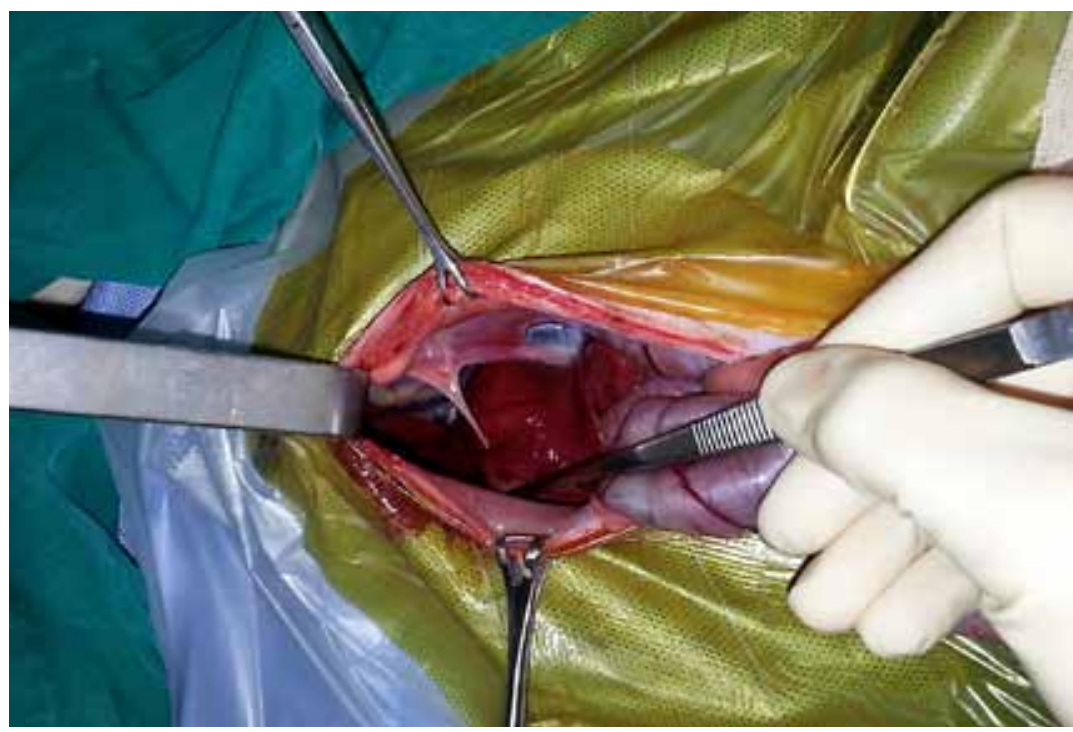

Fig. 4. The diaphragmatic tear of the cat in Figs 1-3. Adhesions between the liver and diaphragm were observed and detached by gentle dissection. The liver and other abdominal organs were returned to the abdominal cavity. 